\title{
Microwave Assisted Surfactant-Thermal Synthesis of Metal-Organic Framework Materials
}

\author{
Cory Forsyth ${ }^{1}$, Tyler Taras ${ }^{1}$, Adam Johnson ${ }^{1}$, Jessica Zagari ${ }^{1}$, Crystal Collado ${ }^{2}$, \\ Markus M. Hoffmann ${ }^{1, *(D)}$ and Carly R. Reed ${ }^{1, *(D)}$ \\ 1 SUNY Brockport, Department of Chemistry and Biochemistry, Brockport, NY 14420, USA; \\ cfors2@brockport.edu (C.F.); ttara1@brockport.edu (T.T.); ajohn8@brockport.edu (A.J.); \\ jzaga2@brockport.edu (J.Z.) \\ 2 Department of Chemistry, Natural Sciences Complex, The University at Buffalo SUNY, Buffalo, \\ NY 14260, USA; collado2@buffalo.edu \\ * Correspondence: mhoffman@brockport.edu (M.M.H.); creed@brockport.edu (C.R.R.)
}

Received: 12 June 2020; Accepted: 24 June 2020; Published: 30 June 2020

check for updates

Featured Application: The novel method of combining microwave heating with nonionic surfactants as reaction medium should be generally applicable for the synthesis of metal-organic framework materials as illustrated in this article.

\begin{abstract}
This research explores the application of surfactants as green solvents for the rapid microwave synthesis of metal-organic framework (MOF) materials. Lead, copper, and iron metal-organic framework materials were synthesized using surfactant-thermal microwave synthesis. The MOF materials were characterized by powder X-ray diffraction, infrared spectroscopy, scanning electron microscopy, and thermogravimetric analysis. With the exception of the iron MOF, which was expected to be amorphous, the MOF materials are crystalline, though generally exhibiting smaller crystals than those achieved with traditional solvothermal synthesis. This green synthetic method reduced synthesis time and reduced the use of traditional organic solvents as the reaction media.
\end{abstract}

Keywords: chemistry; surfactant; metal-organic framework; rapid synthesis; microwave; green solvents

\section{Introduction}

Metal-organic frameworks (MOFs) are porous materials that have attracted much attention in the past two decades due to their tunable structure and pore size. Applications for MOFs have been found in energy storage, chemical separation, chemical sensing, catalysis, and the biomedical field [1-5]. MOFs have been synthesized using many techniques including: slow evaporation, diffusion, direct mixing, solvothermal, ionothermal, sonochemical, mechanochemical, electrochemical, microwave, microfluidic synthesis, and dry-gel conversion [4]. Many of these synthetic methods involve the use of structurally directing solvents such as dimethylformamide, diethylformamide, and dimethylamine (DMF, DEF, and DMA, respectively) which are, however, problematic because they are toxic or carcinogenic [6-9]. These solvents also cause environmental issues when synthesizing MOFs on an industrial scale because volatile organic compounds are a major source of industrial pollution. As solvent replacement options, ionic liquids (ILs), which are salts that are liquid below $100{ }^{\circ} \mathrm{C}$ and possess a negligible vapor pressure making them inflammable, have been successfully used to synthesize MOFs [10,11]. However, many ILs are corrosive, their toxicity to human health and the environment is not well established, and their cost limits their use on an industrial scale [12]. 
Nonionic surfactants have been widely used as an additive in MOF synthesis, in addition to organic solvents, to affect the crystal size, shape, and surface properties as well as pore morphology. However, only in the last few years have surfactants, mainly polyethylene glycol (PEG), been explored as the main reaction media for MOFs [12-20]. Beyond MOF synthesis, polyethylene glycol (PEG) has been employed as an efficient "green solvent" for synthetic chemistry for many years, since it possesses a very low vapor pressure similar to ionic liquids, but is nontoxic and biodegradable [21,22]. PEG can dissolve a wide range of solutes as exemplified in intense recent research to employ PEG as a solvent for multi-component ("one-pot") synthesis reactions [23-42]. Even mineral salts may be soluble in PEG [43]. Very intriguingly, surfactant-thermal synthesis has provided interesting results in the structure and purification of MOFs. In the reaction between zinc acetate and trimesic acid, with all other reaction conditions the same, varying the surfactant media from PEG 400 to octanoic acid changed the connectivity and crystal structure of the MOFs produced [18]. In another instance, nickel nitrate was reacted with bipyridine and $\mathrm{H}_{4} \mathrm{~L}$ in water and resulted in a mixture of two products. However, when the reaction was repeated in a PEG 400 (400 denotes the average molecular weight) and water mixture, pure product 1 was produced, whereas, in n-octanoate, pure product 2 was produced [19]. These examples demonstrate that utilizing PEG as the reaction medium for MOF synthesis may influence the MOF structure, crystal size and shape, as well as, pore size and shape, all of which are very important for the separating, sensing, storing, and catalyzing ability of MOFs $[18,19,44]$.

Microwave synthesis has also been shown to be a valuable tool in MOF synthesis as well as a synthetic variation that can impact crystal and pore size and shape [1,44]. One of the most widely studied MOFs, (HKUST-1) $\mathrm{Cu}_{3}(\mathrm{BTC})_{2}$, has been synthesized via microwave irradiation under a variety of conditions in traditional solvents [45-49]. $\mathrm{Cu}_{3}(\mathrm{BTC})_{2}$ has also been synthesized at room temperature in surfactants [50]. This study explores the combination of the two environmentally friendly methodologies of using nonionic surfactants and microwave heating for the synthesis of MOFs. A total of five different MOFs (denoted as MOF-1 to MOF-5) have been synthesized and characterized to explore the impact of surfactant-thermal microwave synthesis on their formation and resulting morphologies.

\section{Materials and Methods}

\subsection{General}

Lead nitrate was purchased from Alfa Aesar Chemicals, copper (II) nitrate trihydrate from Acros Organics, and iron (III) chloride hexahydrate and sodium hydroxide from Fisher Scientific. Trimesic acid $\left(\mathrm{H}_{3} \mathrm{BTC}\right)$, 5-tert-butylisophthalic acid $\left(\mathrm{H}_{2} \mathrm{TBiP}\right)$, Basolite ${ }^{\circledR} \mathrm{C} 300$, Basolite ${ }^{\circledR} \mathrm{F} 300$, and diethyl ether were purchased from Sigma Aldrich. Basolite ${ }^{\circledR}$ C300 and F300 were stored in a nitrogen filled glovebox between experiments. All other organic solvents were purchased from Pharmco by Greenfield Global. PEG 400 and nonanoic acid were purchased from Acros Organics. PEG 200 and Surfonic ${ }^{\circledR}$ JL 80X were donated by Rochester Midland Corp, who purchased these in large quantities from Dow Chemical Company and Huntsman, respectively. All chemicals were used as received. The exact composition of the polydisperse PEG 200, PEG 400, and Surfonic ${ }^{\circledR}$ JL 80X has been provided elsewhere [51,52].

\subsection{Synthesis}

(MOF-1) Synthesis of $\left[\mathrm{Pb}_{4}(\mathrm{TBiP})_{4}(\text { solvent })_{\mathrm{x}}\right] . \mathrm{Pb}\left(\mathrm{NO}_{3}\right)_{2}(0.435 \mathrm{~g}, 1.31 \mathrm{mmol})$, 5-tert-butylisophthalic acid $(0.305 \mathrm{~g}, 1.37 \mathrm{mmol})$, and PEG $200(10 \mathrm{~mL})$ were combined in a GlassChem microwave vessel and magnetically stirred for $30 \mathrm{~min}$ before being placed in a microwave reactor. The reaction mixture was irradiated in the CEM Mars 6; ramped for $20 \mathrm{~min}$ to $180^{\circ} \mathrm{C}$ and held at $180^{\circ} \mathrm{C}$ for $1.5 \mathrm{~h}$. The reaction vessel was then allowed to cool to room temperature. The product was washed with $2 \times 10 \mathrm{~mL}$ DMF, $10 \mathrm{~mL}$ ethanol, $10 \mathrm{~mL}$ diethyl ether and then air dried. Yield: $0.259 \mathrm{~g}$.

(MOF-2) Synthesis of $\left[\mathrm{Cu}_{3}(\mathrm{BTC})_{2}\right] . \mathrm{Cu}\left(\mathrm{NO}_{3}\right)_{2} \cdot 3 \mathrm{H}_{2} \mathrm{O}(0.919 \mathrm{~g}, 3.80 \mathrm{mmol})$, trimesic acid (0.444 g, $2.115 \mathrm{mmol})$, and PEG $400(24 \mathrm{~mL})$ were combined in an EasyPrep microwave vessel and magnetically 
stirred for $18 \mathrm{~min}$. The stir bar was removed, the vessel sealed, and placed in the microwave. The reaction mixture was ramped for $10 \mathrm{~min}$ to $140{ }^{\circ} \mathrm{C}$ and held for $1 \mathrm{~h}$ using a max power of $500 \mathrm{~W}$. The reaction vessel was then allowed to cool to room temperature. The product was washed with $3 \times 100 \mathrm{~mL}$ of water and $2 \times 100 \mathrm{~mL}$ of methanol for $30 \mathrm{~min}$ for each wash and then air dried. Yield: $0.817 \mathrm{~g}$.

(MOF-3) Synthesis of $\left[\mathrm{Cu}_{3}(\mathrm{BTC})_{2}\right] . \mathrm{Cu}\left(\mathrm{NO}_{3}\right)_{2} \cdot 3 \mathrm{H}_{2} \mathrm{O}(0.865 \mathrm{~g}, 3.58 \mathrm{mmol})$, trimesic acid $(0.412 \mathrm{~g}$, $1.96 \mathrm{mmol})$, and Surfonic ${ }^{\circledR}$ JL 80X $(24 \mathrm{~mL})$ were combined in an EasyPrep microwave vessel and magnetically stirred for $13 \mathrm{~min}$ at $340 \mathrm{rpm}$. The stir bar was removed, the vessel sealed, and placed in the microwave. The reaction mixture was ramped for $10 \mathrm{~min}$ to $140^{\circ} \mathrm{C}$ and held for $1 \mathrm{~h}$ using a max power of $500 \mathrm{~W}$. The reaction vessel was then allowed to cool to room temperature. The product was washed with $3 \times 100 \mathrm{~mL}$ of water and $2 \times 100 \mathrm{~mL}$ of methanol for $30 \mathrm{~min}$ for each wash and then air dried. Yield: $0.382 \mathrm{~g}$.

(MOF-4) Synthesis of $\left[\mathrm{Cu}_{3}(\mathrm{BTC})_{2}\right] . \mathrm{Cu}\left(\mathrm{NO}_{3}\right)_{2} \cdot 3 \mathrm{H}_{2} \mathrm{O}(0.909 \mathrm{~g}, 3.77 \mathrm{mmol})$, trimesic acid $(0.434 \mathrm{~g}$, $2.07 \mathrm{mmol})$, and nonanoic acid $(24 \mathrm{~mL})$ were combined in an EasyPrep microwave vessel and magnetically stirred for $20 \mathrm{~min}$. The stir bar was removed, the vessel sealed, and placed in the microwave. The reaction mixture was ramped for $10 \mathrm{~min}$ to $140{ }^{\circ} \mathrm{C}$ and held for $1 \mathrm{~h}$ using a max power of $500 \mathrm{~W}$. The reaction vessel was then allowed to cool to room temperature. The product was washed with $3 \times 100 \mathrm{~mL}$ of water and $2 \times 100 \mathrm{~mL}$ of methanol for $30 \mathrm{~min}$ for each wash and then air dried. Yield: $0.300 \mathrm{~g}$.

(MOF-5) Synthesis of [Fe(BTC)]. Fe-BTC was synthesized via a modified synthesis of Sanchez-Sanchez et al. [53] $\mathrm{FeCl}_{3} \cdot 6 \mathrm{H}_{2} \mathrm{O}(1.00 \mathrm{~g}$, $3.70 \mathrm{mmol})$ was combined with 20,000 g of PEG 400 to create a suspension. Trimesic acid $(0.529 \mathrm{~g}, 2.52 \mathrm{mmol})$, sodium hydroxide $(0.295 \mathrm{~g}, \mathrm{mmol})$, and 20,000 $\mathrm{g}$ of water were combined to create a second mixture. The PEG 400 mixture was combined with the aqueous mixture in an EasyPrep microwave vessel, the vessel sealed, and placed in the microwave. The reaction mixture was ramped for $2 \mathrm{~min}$ to $40^{\circ} \mathrm{C}$ and held for $2 \mathrm{~min}$ using a max power of $500 \mathrm{~W}$. The reaction vessel was then allowed to cool to room temperature. The product was washed with $2 \times 100 \mathrm{~mL}$ of water and $3 \times 100 \mathrm{~mL}$ of ethanol for 30-60 min for each wash and then air dried. Yield: $0.397 \mathrm{~g}$.

\subsection{Characterization}

Fourier-transform infrared (FT-IR) spectra were recorded with a pure solid sample in percent reflectance mode on a Nicolet 380 FT-IR with a Smart Miracle Attenuated Total Reflectance (ATR) accessory. Powder X-ray diffraction (PXRD) patterns were obtained with a Panalytical XPro diffractometer using a CuK radiation source. The HKUST-1 PXRD was simulated in Mercury 2020.1 from a previously published single crystal structure [54]. The crystal size and morphology were examined using a scanning electron microscope (SEM). SEM images were recorded using a Hitachi model SU70 field emission SEM with an Oxford energy-dispersive X-ray spectrometer attachment. Samples for study were mounted on carbon tape and coated with evaporated carbon. Images were acquired using $2 \mathrm{kV}$ at various magnifications $(100 \times-10,000 \times)$. Thermogravimetric analysis (TGA) was performed at the Rochester Institute of Technology Chemical Analysis Laboratory with a TA Instruments $\mathrm{Q} 500 \mathrm{TGA}$ using a $5.00{ }^{\circ} \mathrm{C} / \mathrm{min}$ ramp to $600-800^{\circ} \mathrm{C}$ under nitrogen.

\section{Results and Discussion}

MOFs containing lead, copper, and iron were synthesized via microwave irradiation in surfactant reaction media. PEG 200 worked well for the lead containing MOF (MOF-1), while with the copper MOFs, PEG 200 led to the formation of visible amounts of $\mathrm{CuO}$ and, therefore, PEG 400, Surfonic ${ }^{\circledR}$ JL 80X, or nonanoic acid were used as alternatives. In keeping with the PEG theme, and since PEG 400 was a successful reaction media for the copper MOF synthesis, it was also carried through to the synthesis of the iron MOF (MOF-5). For the lead and copper MOFs, 100\% surfactant was used as the reaction medium, while for the iron MOF (MOF-5), a 50/50 wt. \% of PEG 400/water mixture was 
used as the reaction medium. Surfactants in combination with microwave irradiation provided more efficient synthetic conditions, in most cases reducing reaction times from days to hours and eliminating commonly used organic solvents such as DMF.

MOFs 1-5 were each characterized using FT-IR spectroscopy, powder X-ray diffraction, scanning electron microscopy and thermogravimetric analysis. The IR spectrum of MOF- 1 is compared to that of 5-tert-butylisophthalic acid in Figure S1, where the disappearance of: the -OH stretching band $\left(3300-2500 \mathrm{~cm}^{-1}\right)$, the normal dimeric carboxylic $\mathrm{C}=\mathrm{O}$ stretch $\left(1700 \mathrm{~cm}^{-1}\right)$, and the dimeric $\mathrm{C}-\mathrm{O}$ stretch $\left(1290 \mathrm{~cm}^{-1}\right)$ can be observed as well as the ingrowth of the asymmetric carboxylate stretch at $1538 \mathrm{~cm}^{-1}$. These changes in spectra from neat carboxylic acid to reaction product indicate the 5-tert-butylisophthalate ligand is now bound to the lead ion in MOF-1. A lead 5-tert-butylisophthalic acid MOF was previously synthesized by Liu et al. via conventional heating for 3 days in DMF with the formula, $\left[\mathrm{Pb}_{4}\left(\mathrm{C}_{12} \mathrm{H}_{12} \mathrm{O}_{4}\right)_{4}(\mathrm{DMF})_{4}\right]$ [55]. While the reaction conditions of MOF-1 did not incorporate DMF, the IR spectrum, PXRD, and TGA (Figures 1, 2 and S1), all appear similar to those of $\left[\mathrm{Pb}_{4}\left(\mathrm{C}_{12} \mathrm{H}_{12} \mathrm{O}_{4}\right)_{4}(\mathrm{DMF})_{4}\right]$ [55]. This indicates a $\left.\left[\mathrm{Pb}_{4}\left(\mathrm{C}_{12} \mathrm{H}_{12} \mathrm{O}_{4}\right)_{4} \text { (solvent) }\right)_{\mathrm{x}}\right]$ like MOF formed from microwave irradiation in PEG 200, either without any coordinating solvents or with water molecules (small amounts present in PEG 200) in place of the DMF molecules. As is expected with microwave irradiation, the crystals of MOF-1 are much smaller than those grown over multiple days by Liu et al. using solvothermal methods (Figure 2) [55]. As shown in Figure 2, aggregates of indistinct small crystals formed in the microwave reaction make it difficult to achieve a single crystal for XRD analysis. TGA analysis of MOF-1 shows thermal stability up to $421^{\circ} \mathrm{C}$ (Figure S2).

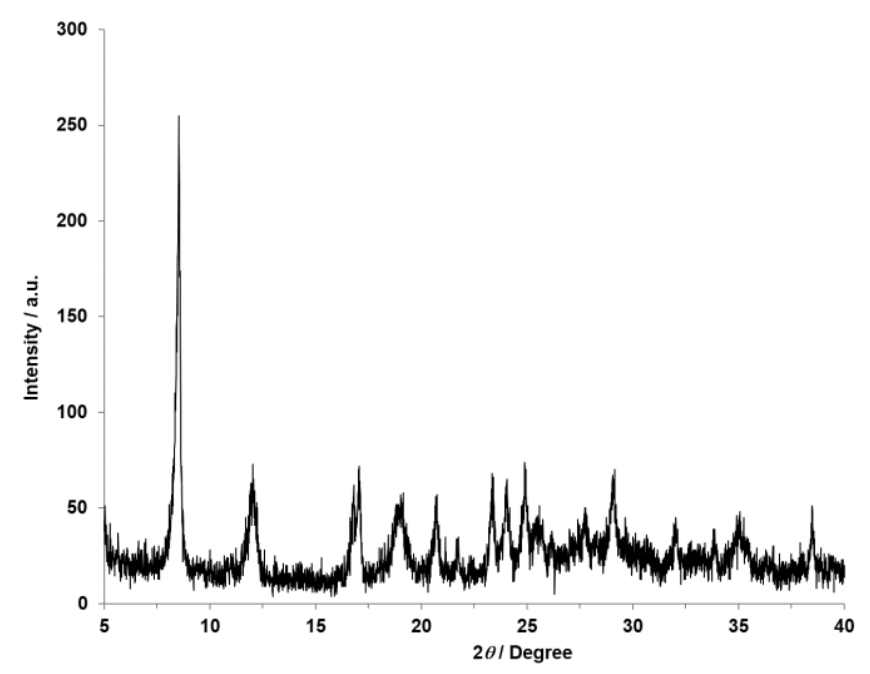

Figure 1. Powder X-ray diffractogram of metal-organic framework (MOF)-1.

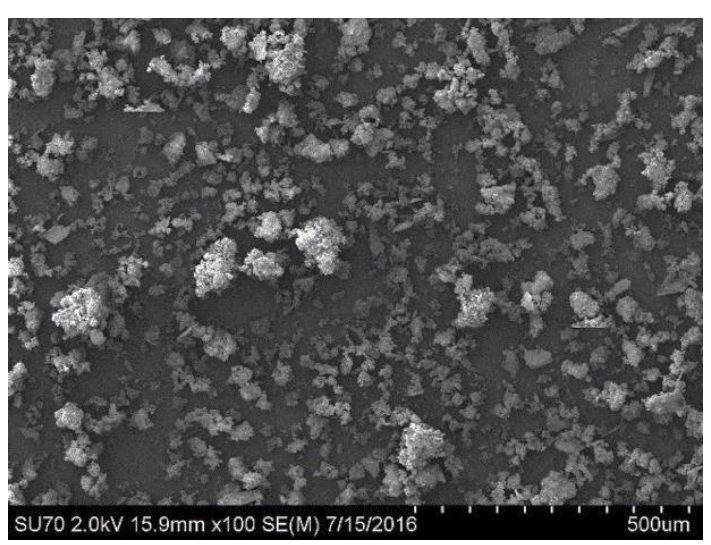

(a)

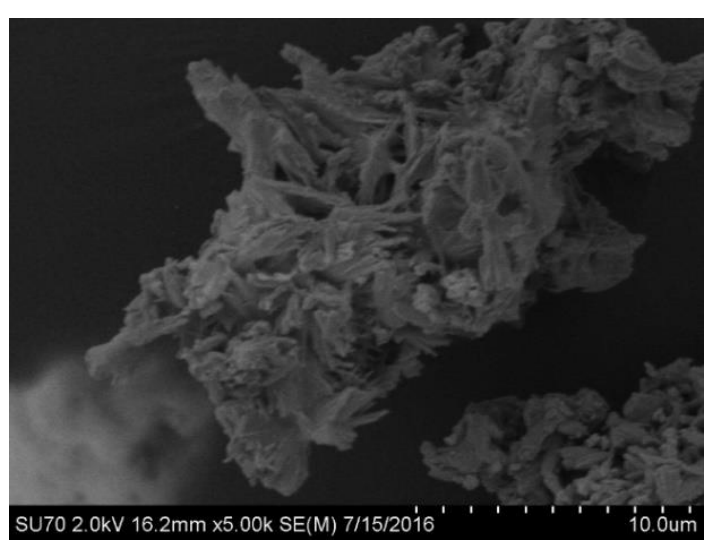

(b)

Figure 2. SEM Images of MOF-1. Increasing magnification from $100 \times(\mathbf{a})$ to $5000 \times(\mathbf{b})$. 
MOFs 2-4 were synthesized via several different combinations of copper nitrate trihydrate, trimesic acid, and surfactant. The IR spectra of MOFs $2-4$ are plotted with commercially available HKUST-1 (Basolite $\left.{ }^{\circledR} \mathrm{C} 300\right),\left[\mathrm{Cu}_{3}(\mathrm{BTC})_{2}\right]$, clearly showing the same vibrational frequencies (Figure S3). PXRD analysis also confirms the structural similarity in spite of the variation in reaction media (Figure 3). The SEM images (Figure 4) of MOFs 2-4 show a difference in morphologies as the surfactant is varied. All form aggregates of microcrystals. MOFs 2 and 3 appear to be the most crystalline, visually. MOF- 2 crystal sizes are in the order of $\sim 0.25-1.0 \mu \mathrm{m}$, while MOF-3 has slightly larger crystal sizes $(\sim 0.5-1.5 \mu \mathrm{m})$. MOF-4 displays the smallest surface features, appearing to be the least crystalline. These crystal sizes are smaller than those reported by conventional heating in water and ethanol of $\geq 20 \mu \mathrm{m}$, yet larger than those conventionally synthesized in PEG 400/P104 at 2-3 nm [45,50]. However, the presence of distinct and sharp PXRD peaks, matching those of commercially available Basolite ${ }^{\circledR}$ C300, supports all being crystalline products. MOFs $2-4$ demonstrate consistent thermal stability up to 355-360 ${ }^{\circ} \mathrm{C}$ (Figures S4-S6), at which point they degrade to $\mathrm{CuO}$ consistent with prior observation by Xue et al. [50].

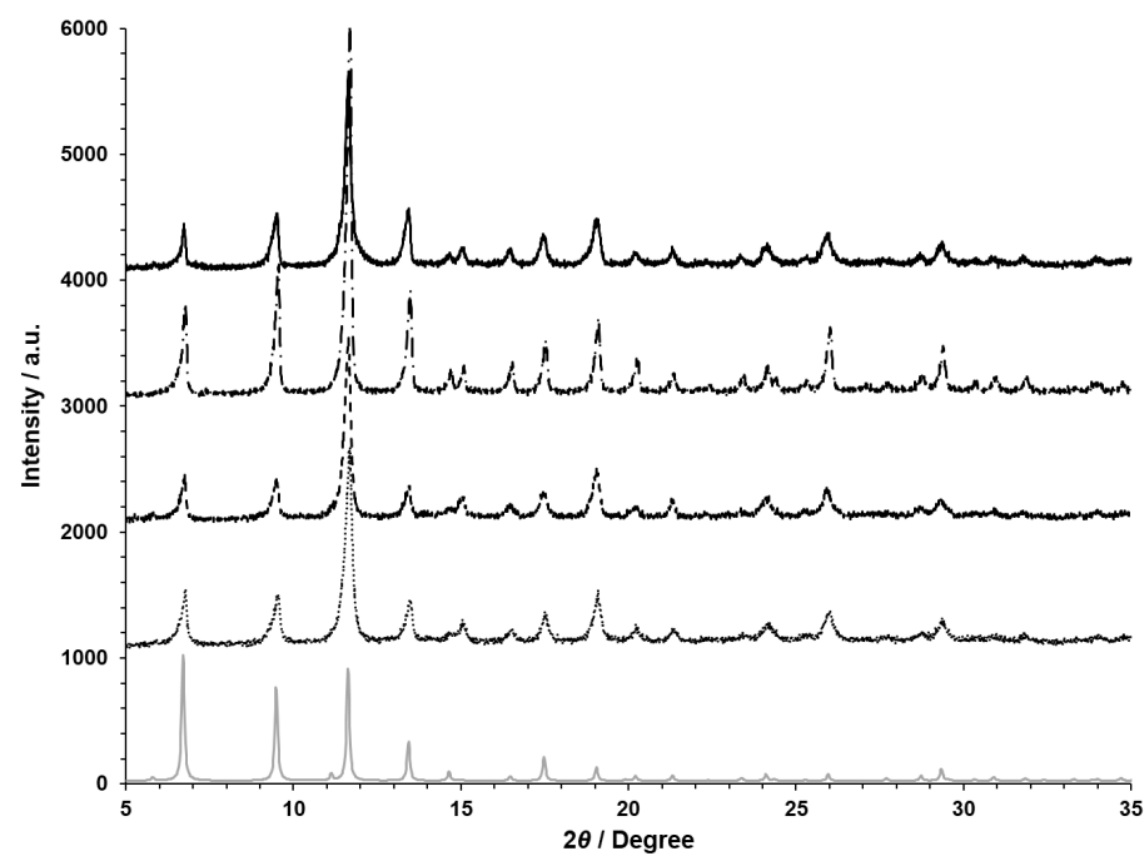

Figure 3. Powder X-ray diffractograms (from top to bottom) of: commercially available Basolite C300 (Cu-BTC; HKUST-1) (black solid line), MOF-2 (black dashed-dot line), MOF-3 (black short dashed line), MOF-4 black (dotted line), and simulated (solid gray).

MOF-5 was synthesized via a combination of iron (III) chloride hexahydrate, trimesic acid, and PEG 400 in addition to water and sodium hydroxide. MOF- 5 was the only MOF synthesized here that did not contain a $100 \%$ surfactant reaction medium due to the need to adjust the $\mathrm{pH}$ using sodium hydroxide solution [53]. The IR spectrum of MOF-5 in Figure S7 is plotted with commercially available amorphous Fe-BTC (Basolite-F300). Both IR spectra in Figure S7 exhibit the same vibrational frequencies. The PXRD analysis of MOF-5 (Figure 5) also confirms the structural similarity to amorphous Fe-BTC (Figure 5) [53]. The SEM images of MOF- 5 also confirm the amorphous quality of this product, with no observable crystalline structures (Figure 6). Additionally, TGA analysis of MOF-5 (Figure S8) is consistent with the known decomposition to $\mathrm{Fe}_{2} \mathrm{O}_{3}$ at $336^{\circ} \mathrm{C}$ [53]. 

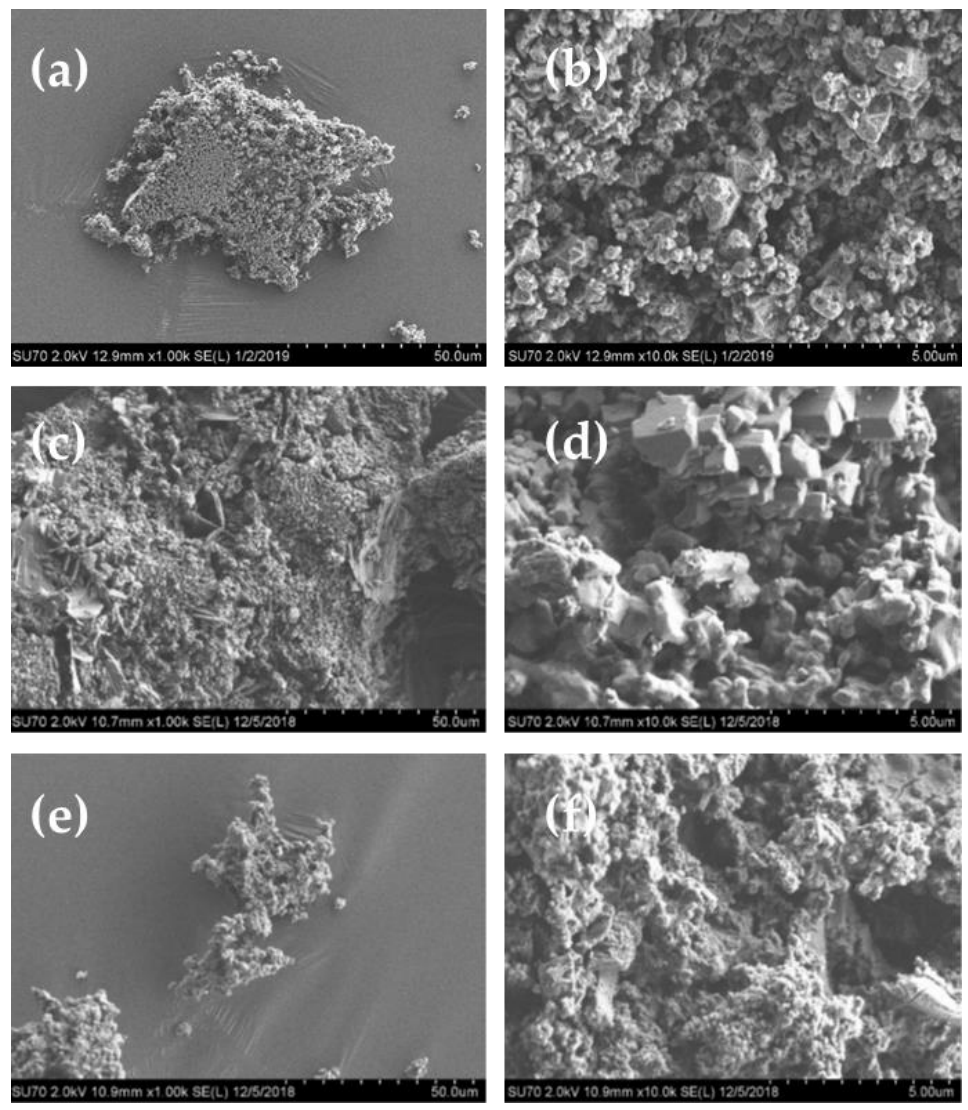

Figure 4. SEM images of MOF-2. Increasing magnification from $1000 \times(a)$ to $10,000 \times(b)$. SEM images of MOF-3. Increasing magnification from $1000 \times$ (c) to $10,000 \times(d)$. SEM images of MOF-4. Increasing magnification from $1000 \times(\mathbf{e})$ to $10,000 \times(\mathbf{f})$.

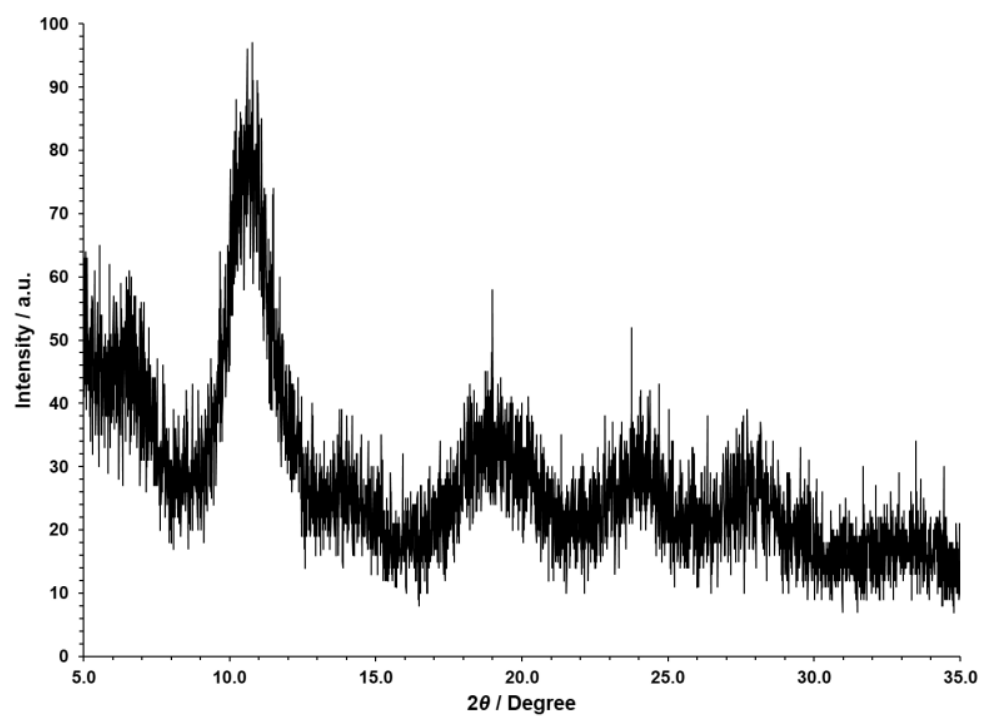

Figure 5. Powder X-ray diffractogram of MOF-5. 


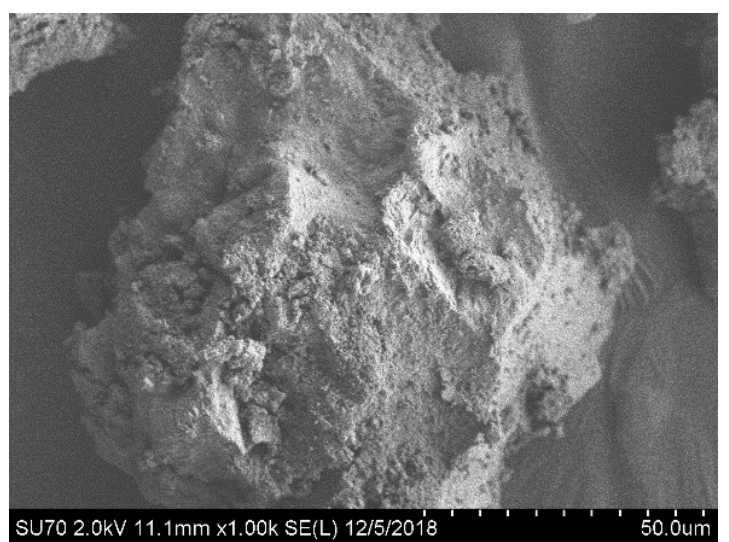

(a)

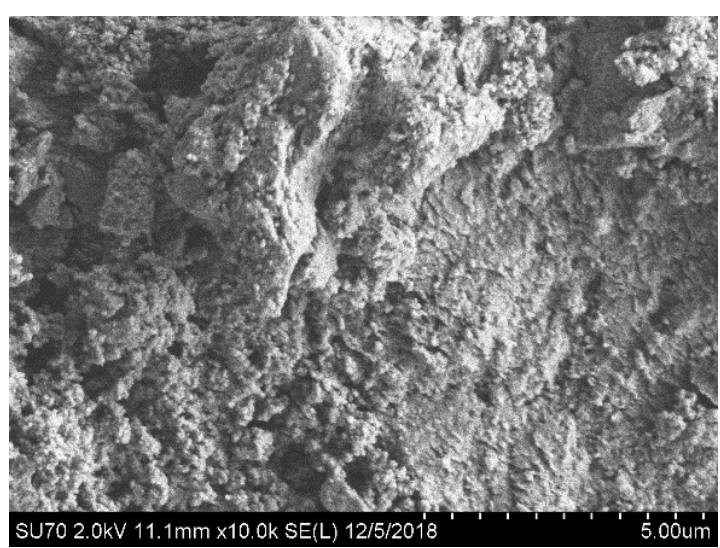

(b)

Figure 6. SEM images of MOF-5. Increasing magnification from $1000 \times(\mathbf{a})$ to $10,000 \times(\mathbf{b})$.

\section{Conclusions}

In conclusion, we have applied surfactant-thermal microwave synthesis for the successful formation of MOF materials containing lead, copper, and iron. These findings illustrate that the elimination of toxic organic solvents and reduced synthesis time from days to hours with associated reduced energy consumption are feasible with surfactant-thermal microwave synthesis of MOFs. The obtained MOF products in this study using surfactant-thermal microwave synthesis were generally crystalline but with smaller crystal sizes, compared to MOFs synthesized with traditional methods.

Supplementary Materials: Infrared spectra and thermogravimetic analysis of all samples are available online at http://www.mdpi.com/2076-3417/10/13/4563/s1, Figure S1: Infrared spectrum of MOF-1 (solid line) and 5-tert-butylisophthalic acid (dotted line), Figure S2: TGA of MOF-1, Figure S3: Infrared spectra (from top to bottom) of: commercially available Basolite C300 (Cu-BTC; HKUST-1) (solid line); MOF-2 (long dashed line); MOF-3 (short dashed line); and MOF-4 (dotted line), Figure S4: TGA of MOF-2, Figure S5: TGA of MOF-3, Figure S6: TGA of MOF-4, Figure S7: Infrared spectra (from top to bottom) of: commercially available Basolite F300 (Fe-BTC) (solid line); MOF-5 (dashed line), Figure S8: TGA of MOF-5.

Author Contributions: Conceptualization, M.M.H. and C.R.R.; Data curation, C.F., A.J., C.C. and C.R.R.; Formal analysis, C.C. and C.R.R.; Funding acquisition, M.M.H. and C.R.R.; Investigation, C.F., T.T., A.J., J.Z., C.C., M.M.H. and C.R.R.; Methodology, C.C., M.M.H. and C.R.R.; Project administration, M.M.H. and C.R.R.; Supervision, M.M.H. and C.R.R.; Visualization, C.C. and C.R.R.; Writing—original draft, C.F., T.T., A.J., J.Z., C.C., M.M.H. and C.R.R.; Writing-review and editing, C.F., T.T., A.J., J.Z., C.C., M.M.H. and C.R.R. All authors have read and agreed to the published version of the manuscript.

Funding: Cory Forsyth: Tyler Taras, Adam Johnson, and Jessica Zagari all received summer undergraduate research stipends from SUNY Brockport Morris Fellowship for Summer Research (Cory Forsyth and Tyler Taras), Undergraduate Research Fellowship in Chemistry (Jessica Zagari) and Summer Undergraduate Research Program (Adam Johnson).

Acknowledgments: We thank Rochester Midland Corporation for providing several nonionic surfactants. We thank Tom Allston for the collection of thermogravimetric analysis data at the Rochester Institute of Technology Chemical Analysis Lab.

Conflicts of Interest: The authors declare no conflict of interest. The funders had no role in the design of the study; in the collection, analyses, or interpretation of data; in the writing of the manuscript, or in the decision to publish the results.

\section{References}

1. Khan, N.A.; Jhung, S.H. Synthesis of metal-organic frameworks (MOFs) with microwave or ultrasound: Rapid reaction, phase-selectivity, and size reduction. Coord. Chem. Rev. 2015, 285, 11-23. [CrossRef]

2. Liu, J.; Chen, L.; Cui, H.; Zhang, J.; Zhang, L.; Su, C.Y. Applications of metal-organic frameworks in heterogeneous supramolecular catalysis. Chem. Soc. Rev. 2014, 43, 6011-6061. [CrossRef]

3. Zhang, X.; Wang, W.; Hu, Z.; Wang, G.; Uvdal, K. Coordination polymers for energy transfer: Preparations, properties, sensing applications, and perspectives. Coord. Chem. Rev. 2015, 284, 206-235. [CrossRef] 
4. Kathalikkattil, A.C.; Babu, R.; Tharun, J.; Roshan, R.; Park, D.W. Advancements in the Conversion of Carbon Dioxide to Cyclic Carbonates Using Metal Organic Frameworks as Catalysts. Catal. Surv. Asia 2015, 19, 223-235. [CrossRef]

5. Dhakshinamoorthy, A.; Asiri, A.M.; Garcia, H. Metal-Organic Frameworks as Catalysts for Oxidation Reactions. Chem. Eur. J. 2016, 22, 8012-8024. [CrossRef]

6. Seetharaj, R.; Vandana, P.V.; Arya, P.; Mathew, S. Dependence of solvents, pH, molar ratio and temperature in tuning metal organic framework architecture. Arab. J. Chem. 2016. [CrossRef]

7. Dimethylamine; Aldrich: St. Louis, MO, USA, 2020. Available online: https://www.merckmillipore.com/JP/en/ product/Dimethylamine,MDA_CHEM-822033 (accessed on 12 June 2020).

8. N,N-Diethylformamide; Aldrich: St. Louis, MO, USA, 2020. Available online: https://www.merckmillipore. com/HK/en/product/NN-Diethylformamide,MDA_CHEM-821752 (accessed on 12 June 2020).

9. N,N-Dimethylformamide; Aldrich: St. Louis, MO, USA, 2020. Available online: https://www.merckmillipore. com/JP/en/product/NN-Dimethylformamide,MDA_CHEM-100397 (accessed on 12 June 2020).

10. Aidoudi, F.H.; Morris, R.E. CHAPTER 10 Ionothermal Synthesis. In Catalysis in Ionic Liquids: From Catalyst Synthesis to Application; The Royal Society of Chemistry: London, UK, 2014; pp. 508-536. ISBN 978-1-84973-603-9.

11. Zhang, B.; Zhang, J.; Han, B. Assembling Metal-Organic Frameworks in Ionic Liquids and Supercritical $\mathrm{CO}_{2}$. Chem. Asian J. 2016, in press. [CrossRef]

12. Gao, J.; Ye, K.; He, M.; Xiong, W.W.; Cao, W.; Lee, Z.Y.; Wang, Y.; Wu, T.; Huo, F.; Liu, X.; et al. Tuning metal-carboxylate coordination in crystalline metal-organic frameworks through surfactant media. J. Solid State Chem. 2013, 206, 27-31. [CrossRef]

13. Xiong, W.W.; Zhang, Q. Surfactants as Promising Media for the Preparation of Crystalline Inorganic Materials. Angew. Chem. Int. Ed. 2015, 54, 11616-11623. [CrossRef]

14. Xu, H.; Gao, J.; Wang, J.; Qian, X.; Song, R.; Cui, Y.; Yang, Y.; Qian, G. Surfactant-thermal method to synthesize a new Zn(II)-trimesic MOF with confined $\mathrm{Ru}(\mathrm{bpy})_{3}{ }^{2+}$ complex. J. Solid State Chem. 2015, 226, $295-298$. [CrossRef]

15. Yu, X.; Toh, Y.S.; Zhao, J.; Nie, L.; Ye, K.; Wang, Y.; Li, D.; Zhang, Q. Surfactant-thermal method to prepare two new cobalt metal-organic frameworks. J. Solid State Chem. 2015, 232, 14-18. [CrossRef]

16. Gao, J.; He, M.; Lee, Z.Y.; Cao, W.; Xiong, W.W.; Li, Y.; Ganguly, R.; Wu, T.; Zhang, Q. A surfactant-thermal method to prepare four new three-dimensional heterometal-organic frameworks. Dalton Trans. 2013, 42, 11367. [CrossRef]

17. Lu, H.S.; Bai, L.; Xiong, W.W.; Li, P.; Ding, J.; Zhang, G.; Wu, T.; Zhao, Y.; Lee, J.M.; Yang, Y.; et al. Surfactant Media To Grow New Crystalline Cobalt 1,3,5-Benzenetricarboxylate Metal-Organic Frameworks. Inorg. Chem. 2014, 53, 8529-8537. [CrossRef] [PubMed]

18. Gao, J.; Ye, K.; Yang, L.; Xiong, W.W.; Ye, L.; Wang, Y.; Zhang, Q. Growing Crystalline Zinc-1,3,5-benzenetricarboxylate Metal-Organic Frameworks in Different Surfactants. Inorg. Chem. 2014, 53, 691-693. [CrossRef] [PubMed]

19. Zhao, J.; Wang, Y.; Dong, W.; Wu, Y.; Li, D.; Liu, B.; Zhang, Q. A new surfactant-introduction strategy for separating the pure single-phase of metal-organic frameworks. Chem. Commun. 2015, 51, 9479-9482. [CrossRef] [PubMed]

20. Zhao, M.; Lu, Q.; Ma, Q.; Zhang, H. Two-Dimensional Metal-Organic Framework Nanosheets. Small Methods 2017, 1, 1600030. [CrossRef]

21. Alves, C.K. Environmentally Benign Solvents in Organic Synthesis: Current Topics. Curr. Org. Chem. 2005, 9, 195-218. [CrossRef]

22. Chen, J.; Spear, S.K.; Huddleston, J.G.; Rogers, R.D. Polyethylene glycol and solutions of polyethylene glycol as green reaction media. Green Chem. 2005, 7, 64-82. [CrossRef]

23. Zhang, J.; Yao, J.; Liu, J.; Xue, S.; Li, Y.; Wang, C. Four-component reaction between naphthols, substituted $\beta$-nitrostyrenes, substituted benzaldehydes and ammonium acetate in water-PEG-400: An approach to construct polysubstituted naphthofuranamines. RSC Adv. 2015, 5, 48580-48585. [CrossRef]

24. Hese, S.V.; Kamble, R.D.; Mogle, P.P.; Kadam, S.S.; Hebade, M.J.; Ambhore, A.N.; Dawane, B.S. Green synthesis and antimicrobial evaluation of pyrido[1,2-a]pyrimidine-3-carbonitrile derivatives. Pharma Chem. 2015, 7, 249-256. 
25. Wang, Z.; Cao, X.; Yang, Y.; Lu, M. Green and Efficient Methods for One-Pot Aerobic Oxidative Synthesis of Benzimidazoles from Alcohols with TEMPO-PEG4000-NHC-Cu(II) Complex in Water. Synth. Commun. 2015, 45, 1476-1483. [CrossRef]

26. Vivekanand, T.; Vinoth, P.; Agieshkumar, B.; Sampath, N.; Sudalai, A.; Menendez, J.C.; Sridharan, V. Highly efficient regioselective synthesis of pyrroles via a tandem enamine formation-Michael addition-cyclization sequence under catalyst- and solvent-free conditions. Green Chem. 2015, 17, 3415-3423. [CrossRef]

27. Kumar, T.V.; Rao, C.R.K.; Mukkanti, K.; Mainkar, P.S. Polyethylene glycol (PEG-400) as an efficient and recyclable reaction medium for one-pot synthesis of substituted pyrroles under catalyst-free conditions. Asian J. Chem. 2015, 27, 1457-1461. [CrossRef]

28. Rajeswari, M.; Sindhu, J.; Singh, H.; Khurana, J.M. An efficient, green synthesis of novel regioselective and stereoselective indan-1,3-dione grafted spirooxindolopyrrolizidine linked 1,2,3-triazoles via a one-pot five-component condensation using PEG-400. RSC Adv. 2015, 5, 39686-39691. [CrossRef]

29. Khan, M.N.; Karamthulla, S.; Choudhury, L.H.; Faizi, M.S. Ultrasound assisted multicomponent reactions: A green method for the synthesis of highly functionalized selenopyridines using reusable polyethylene glycol as reaction medium. RSC Adv. 2015, 5, 22168-22172. [CrossRef]

30. Kidwai, M.; Chauhan, R. A Rapid and an Efficient Route to the One-pot, Multicomponent Synthesis of 1H-Pyrazolo[1,2-b]phthalazine-5,10-dione Ring Systems. J. Heterocycl. Chem. 2014, 51, 1689-1696. [CrossRef]

31. Wang, Z.G.; Xia, Y.G.; Jin, Y.; Lu, M. Green and reusable homogeneous oxidative system with ceric ammonium nitrate/[Imim-PEG1000-TEMPO] for efficient aerobic oxidation of alcohols and one-pot synthesis of benzimidazoles from alcohols under ambient conditions. Appl. Organomet. Chem. 2015, 29, $109-112$. [CrossRef]

32. Mogle, P.P.; Kamble, R.D.; Hese, S.V.; Dawane, B.S. Bleaching earth clay (pH 12.5)/PEG-400: An efficient recyclable catalytic system for synthesis of 5,6,7,8-tetrahydroquinoline-3-carbonitrile derivatives. Res. Chem. Intermed. 2014, 41, 4673-4678. [CrossRef]

33. Liang, C.; Tang, Z.; Qian, W.; Shi, C.; Song, H. Ultrasound-promoted synthesis of 2-aminothiophenes accelerated by DABCO utilizing PEG-200 as solvent. J. Chem. Pharm. Res. 2014, 6, 798-802.

34. Nagaraju, A.; Ramulu, B.J.; Shukla, G.; Srivastava, A.; Verma, G.K.; Raghuvanshi, K.; Singh, M.S. Catalyst-free one-pot four-component domino reactions in water-PEG-400: Highly efficient and convergent approach to thiazoloquinoline scaffolds. Green Chem. 2015, 17, 950-958. [CrossRef]

35. Reddy, M.V.; Son, S.M.; Jeong, Y.T. TiO2-SiO2 in PEG: A Highly Efficient Green Catalytic System for One-Pot Synthesis of Benzo[a]xanthen-11-ones. J. Heterocycl. Chem. 2014, 51, 1246-1250. [CrossRef]

36. Shen, M.; Wang, J.; Shang, S.; Song, Z. A simple and efficient procedure for the one-pot three-component synthesis of spiro[indoline-3,9'-tetrazolo[5,1-b]quinazoline]-2, $8^{\prime}\left(5^{\prime} \mathrm{H}\right)$-dione in PEG-H2O medium. Chem. Lett. 2014, 43, 1239-1241. [CrossRef]

37. Reddy, A.S.; Reddy, M.N.; Swamy, K.C.K. A simple copper-catalyzed tandem cyclization of ynamides leading to triazolo-1,2,4-benzothiadiazine-1,1-dioxides in PEG-400 medium. RSC Adv. 2014, 4, 28359-28367. [CrossRef]

38. Kadam, A.; Dawane, B.; Pawar, M.; Shegokar, H.; Patil, K.; Meshram, R.; Gacche, R. Development of novel pyrazolone derivatives as inhibitors of aldose reductase: An eco-friendly one-pot synthesis, experimental screening and in silico analysis. Bioorg. Chem. 2014, 53, 67-74. [CrossRef]

39. Sindhu, J.; Singh, H.; Khurana, J.M. A green, multicomponent, regio- and stereo-selective 1,3-dipolar cycloaddition of azides and azomethine ylides generated in situ with bifunctional dipolarophiles using PEG-400. Mol. Divers. 2014, 18, 345-355. [CrossRef] [PubMed]

40. Firouzabadi, H.; Iranpoor, N.; Samadi, A. One-pot synthesis of aryl alkyl thioethers and diaryl disulfides using carbon disulfide as a sulfur surrogate in the presence of diethylamine catalyzed by copper(I) iodide in polyethylene glycol (PEG200). Tetrahedron Lett. 2014, 55, 1212-1217. [CrossRef]

41. Piltan, M.; Moradi, L.; Zarei, S.A.; Rostami, H. One-pot multicomponent synthesis of novel tricyclic pyrrolo[2,1-c][1,4]benzoxazines. Chin. Chem. Lett. 2014, 25, 234-236. [CrossRef]

42. Acharya, A.P.; Kamble, R.D.; Patil, S.D.; Hese, S.V.; Yemul, O.S.; Dawane, B.S. Green method for synthesis of 3-[2-(substituted-phenyl)-2-oxo ethylidene]-1,3-dihydro-indol-2-one and their in vitro antimicrobial activity. Res. Chem. Intermed. 2015, 41, 2953-2959. [CrossRef]

43. McGarvey, P.W.; Hoffmann, M.M. Solubility of Some Mineral Salts in Polyethylene Glycol and Related Surfactants. TSD 2018, 55, 203-209. [CrossRef] 
44. Stock, N.; Biswas, S. Synthesis of Metal-Organic Frameworks (MOFs): Routes to Various MOF Topologies, Morphologies, and Composites. Chem. Rev. 2012, 112, 933-969. [CrossRef]

45. Seo, Y.K.; Hundal, G.; Jang, I.T.; Hwang, Y.K.; Jun, C.H.; Chang, J.S. Microwave synthesis of hybrid inorganic-organic materials including porous $\mathrm{Cu}_{3}(\mathrm{BTC})_{2}$ from $\mathrm{Cu}(\mathrm{II})$-trimesate mixture. Microporous Mesoporous Mater. 2009, 119, 331-337. [CrossRef]

46. Schlesinger, M.; Schulze, S.; Hietschold, M.; Mehring, M. Evaluation of synthetic methods for microporous metal-organic frameworks exemplified by the competitive formation of $\left[\mathrm{Cu}_{2}(\mathrm{btc})_{3}\left(\mathrm{H}_{2} \mathrm{O}\right)_{3}\right]$ and $\left[\mathrm{Cu}_{2}(\mathrm{btc})(\mathrm{OH})\left(\mathrm{H}_{2} \mathrm{O}\right)\right]$. Microporous Mesoporous Mater. 2010, 132, 121-127. [CrossRef]

47. Blanita, G.; Borodi, G.; Lazar, M.D.; Biris, A.R.; Barbu-Tudoran, L.; Coldea, I.; Lupu, D. Microwave assisted non-solvothermal synthesis of metal-organic frameworks. RSC Adv. 2016, 6, 25967-25974. [CrossRef]

48. Diring, S.; Furukawa, S.; Takashima, Y.; Tsuruoka, T.; Kitagawa, S. Controlled Multiscale Synthesis of Porous Coordination Polymer in Nano/Micro Regimes. Chem. Mater. 2010, 22, 4531-4538. [CrossRef]

49. Zou, F.; Yu, R.; Li, R.; Li, W. Microwave-Assisted Synthesis of HKUST-1 and Functionalized HKUST-1-@H3PW12O40: Selective Adsorption of Heavy Metal Ions in Water Analyzed with Synchrotron Radiation. ChemPhysChem 2013, 14, 2825-2832. [CrossRef] [PubMed]

50. Xue, Z.; Zhang, J.; Peng, L.; Han, B.; Mu, T.; Li, J.; Yang, G. Poly(ethylene glycol) Stabilized Mesoporous Metal-Organic Framework Nanocrystals: Efficient and Durable Catalysts for the Oxidation of Benzyl Alcohol. ChemPhysChem 2014, 15, 85-89. [CrossRef]

51. Hoffmann, M.M.; Bothe, S.; Gutmann, T.; Hartmann, F.F.; Reggelin, M.; Buntkowsky, G. Directly vs Indirectly Enhanced 13C in Dynamic Nuclear Polarization Magic Angle Spinning NMR Experiments of Nonionic Surfactant Systems. J. Phys. Chem. C 2017, 121, 2418-2427. [CrossRef]

52. Zagari, J.; Hoffmann, M.M. Polydispersity Analysis of Polyethylene Glycol by Gas and Liquid Chromatography. Chem. Educ. 2019, 24, 30-34.

53. Sanchez-Sanchez, M.; de Asua, I.; Ruano, D.; Diaz, K. Direct Synthesis, Structural Features, and Enhanced Catalytic Activity of the Basolite F300-like Semiamorphous Fe-BTC Framework. Cryst. Growth Des. 2015, 15, 4498-4506. [CrossRef]

54. Chui, S.S.Y.; Lo, S.M.F.; Charmant, J.P.H.; Orpen, A.G.; Williams, I.D. A Chemically Functionalizable Nanoporous Material $\left[\mathrm{Cu}_{3}(\mathrm{TMA})_{2}\left(\mathrm{H}_{2} \mathrm{O}\right)_{3}\right] \mathrm{n}$. Science 1999, 283, 1148-1150. [CrossRef]

55. Liu, L.; Han, Z.B.; Wang, S.M.; Yuan, D.Q.; Ng, S.W. Robust Molecular Bowl-Based Metal-Organic Frameworks with Open Metal Sites: Size Modulation To Increase the Catalytic Activity. Inorg. Chem. 2015, 54, 3719-3721. [CrossRef] [PubMed]

(C) 2020 by the authors. Licensee MDPI, Basel, Switzerland. This article is an open access article distributed under the terms and conditions of the Creative Commons Attribution (CC BY) license (http://creativecommons.org/licenses/by/4.0/). 